\title{
Twenty years ago
}

\section{A parent's voice}

\section{DERMOD MACCARTHY AND RONALD MACKEITH}

\begin{abstract}
'A parent's feelings may be the deepest that anyone can experience, or they may only be exaggerated apprehension. Doctors and nurses when they have to contend with complex medical problems of life and death prefer not to do so in an atmosphere of strong emotion. We, therefore, keep parents at a distance in a crisis and, for further self-protection, though we may pretend this is for the parents' peace of mind, we keep them at a distance at any time when a crisis may occur. Yet parents whose child has died in hospital may afterwards be extremely troubled by their sense of having failed the child in the last days, hours, or minutes, because they were not there to give what comfort and support they could. Is this distress inevitable, even allowing for the need of doctors and nurses to work undisturbed in an emergency?

We have taken the following letter from a mother to the National Association for the Welfare of Children in Hospital as a basis for a general discussion of some of these difficult questions.
\end{abstract}

\footnotetext{
"My little girl, Dawn, was admitted to hospital for a tonsils and adenoids operation when she was 3 years and 3 weeks old and she had never been anywhere without me, was very shy, and did not get on with strangers. I took Dawn to the hospital at $2.15 \mathrm{pm}$ as arranged, was told to undress her and put her to bed. I was allowed to stay with her until 3 o'clock and told that I could return for the visiting hour $5 \mathrm{pm}$ till $6 \mathrm{pm}$. When I returned at 5 o'clock I was told by a little boy in the next bed that Dawn had cried after me ever since I had left her at 3 o'clock, her little face was quite puffed from crying when I left at 6 o'clock. I was told that I could not visit the next day because she was having the operation but they said I could telephone at 12 noon.

Wednesday, 17th. I telephoned at 12 noon and was told that Dawn had had the operation and was satisfactory. I asked if I could visit but was told not to do so after an operation but they said I could ring again at $6 \mathrm{pm}$ if I wanted to. I again telephoned the hospital at $6 \mathrm{pm}$ and was
}

told that Dawn was bleeding heavily but not to worry and ring again at $8 \mathrm{pm}$. This I did and was told that the surgeons had taken her back to the theatre to stop the bleeding and they said I could telephone at $9.30 \mathrm{pm}$. This I did and was told that she had not come round yet but the bleeding had stopped and was told to ring at midnight. This I did and was told that Dawn had come round and was sleeping peacefully. They told me not to worry, to go home to sleep and telephone the hospital at 10.30 am next morning. At this point I must point out that each time I rang up I begged to see my child but they said there was nothing to worry about and that I could not see her.

Thursday, 18th, 10.30 am. I telephoned the hospital, spoke to the ward sister and was told that Dawn was a little improved and that I could visit at 4 o'clock. I arrived at the hospital at $3.50 \mathrm{pm}$ and was asked to wait because the doctor was with Dawn. A few minutes later I was told that Dawn had collapsed but not to worry because the doctor was doing all possible. I asked if I could go to her but was told to wait. As I waited I prayed to God to help my little girl; a few minutes later the ward sister came and said that my dear Dawn had passed away at $4.15 \mathrm{pm}$, so you see although I was there I couldn't go in to see her even though she was dying. They took me to see Dawn then but it was too late for my love to do its work because she had gone to rest.

There had to be a post mortem on my little girl and they found that she had died from bilateral bronchopneumonia. They said that she would have had pneumonia anyway but the doctor couldn't tell before the operation.

Other mothers who had children in Dawn's ward were allowed to see their children because they hadn't had the operation and these mothers have told me that on the day of Dawn's operation she had been returned to the ward and was crying constantly for me and this, I believe, caused the bleeding.

I do believe that my little girl died from pneumonia but I also think that if $I$ had been with her it might have had a different ending because she wouldn't have needed to sob her heart out if I had been by her side, and if she hadn't cried she wouldn't have lost so much blood, and if she hadn't lost the blood then she would have had more strength to fight the pneumonia with.

\footnotetext{
This article first appeared in The Lancet (1965, ii: 1289-91) and is reprinted by kind permission.

Ronald MacKeith died in 1977. Dermod MacCarthy, who retired from paediatric practice in 1978, lives in Buckinghamshire, is in good health, and talks about this topic and many others as cogently and persuasively as ever. Ed.
} 
Who knows, perhaps if I had been with her, I still may not have saved her life but at least I could have given her comfort.

This morning I have done the last thing I can do for my little girl, that is to attend her funeral. If this letter can help you in any way to get another youngster his mother's care after this operation I shall be pleased for you to use it, because after all a nurse's skill cannot mend a child's broken heart, only a mother can do this because there is nothing in the world like a mother's love when a child is ill and upset."

We have no facts from the hospital, and we do not know what was actually happening during this mother's 48 hour separation from her child, but we can be sure that the staff who had the nursing and surgical care of Dawn must have been extremely distressed and no doubt felt that sense of inadequacy which such calamities bring. We can also presume that they hoped, indeed expected, to be able to reintroduce the mother to the convalescent child after the crisis of the postoperative haemorrhage had passed, but until then considered that the mother could make no contribution to the child's recovery, but was likely to distress both herself and the child, and would therefore hinder their efforts on Dawn's behalf. If Dawn had survived, the hospital's advice to the mother not to worry would have appeared to be justified, but should we not admit that we sometimes gamble on the outcome in the hope of saving parents some anxious suspense?

Taken as a mother's eye-view of a crisis and a tragedy there is much to be learnt from this letter. The convictions are simply and poignantly expressed yet with exceptional restraint. What are these convictions and how valid are the mother's inferences?

She says that she learnt from other mothers in the ward that after the operation, Dawn was crying constantly for her, and this she believes caused bleeding. She believes that, if she had been there to comfort her, Dawn would not have cried, would not, therefore, have "lost so much blood," and hence "would have had more strength to fight the pneumonia with." But with complete reasonableness the mother goes on to say "if I had been with her, I still might not have saved her life but at least I could have given her comfort."

Surgeons want their patients to be quiet after tonsillectomy. Crying and restlessness, if severe or prolonged, are considered to dispose to bleeding. The effect on crying of the presence of the mother is variable. But on the whole the older the child, the better prepared she is for what is to happen, and the greater the participation of a parent, before as well as after the operation, the less crying we hear. By contrast the younger the child and the less the participation of the mother, the worse the crying. The distressful and prolonged crying of some children, whom the nurses cannot or have not time to console, may require sedation by injection, but the effect of this is often short lived, and postoperative sedation cannot be put forward as the best solution. There is, therefore, substance in the mother's contention that Dawn might have escaped this complication if the mother had been able to go to her and stay with her. But to be fully effective the mother should, of course, have been able to stay in hospital with Dawn from the moment of admission.

The mother concedes, however, that her influence as a comforter might not have turned the scales. She is, nevertheless, troubled that she was not there simply to relieve her "heartbreak." She feels she let her child down, and this reproach she must now live with. Even the faintest contact a mother has with a dying child mitigates this particular anguish. Access should not, therefore, be denied when hope is running out.

At certain times when her mother wished to be with her, Dawn may, in fact, have been unconscious in oxygen, having a transfusion or one of the other technical nursing and medical procedures that go with a rapidly deteriorating clinical state. Not every mother wants to be, or can stand being, a passive witness to these things, nor do the staff want a mother as an onlooker at such moments. But some mothers do wish to be at the bedside in the terminal stages, and we should have some means of recognising them.

Then there is the question of a parent's right to insist on seeing their child. Has a hospital at present any right to deny access? No; but the staff can make a parent feel that a visit would be so disturbing as to do more harm than good. It is difficult for parents to pit their convictions against the authority of the hospital, and insistence on rights only worsens communication between doctor and parent or nurse and parent. The mother asked repeatedly to see Dawn but was told that she could not, or more probably she was persuaded that it was undesirable and would do more harm than good. Did the staff fear the consequences of the emotional outburst that follows when a mother returns to visit a frightened child and then departs again? But this commotion, admittedly undesirable, can be avoided if the mother is in the hospital to care for the child.

A final point in the letter seems to us even more valid than the others. This child was apparently specially vulnerable to separation from her mother"she had never been anywhere without me, was very shy and did not get on with strangers." She was also at about the age peak for the effects of separation anxiety. That the child would be very distressed by 
the experience as a whole was practically certain, but no allowances for this were made in the visiting arrangements. Vulnerability of this kind is not a concept that has any place in the general run of admission procedures; we have not got to that yet, but this tragedy may bring us to it sooner. A child's vulnerability should be one of the pros and cons considered when deciding the time for a "cold" operation.

To us, there seems to be substance in this mother's plea that her presence with the child might have made a difference, and there is substance in the plea of the National Association for the Welfare of Children in Hospital that the special dependence of very young children should receive more consideration. It should be made possible for a mother to live in hospital with her child-or stay near the child for as long as possible - and for her to help in the simple parts of the child's care. The hospital staff should accept that the mother herself needs to be there, at times may need their support, and that her presence will help the child.' 